\title{
Multicultural Education
}

\author{
Ani Derderian-Aghajanian \\ Washington State University \\ E-mail: ani.ag@hotmail.com/aderderian@wsu.edu
}

\begin{abstract}
"If we knew what we were doing, it wouldn't be called research, would it?" (Albert Einstein). In Diversity Issues in Special Education: Theory, Research, and Practice I will define the diversity perspectives within the context of research, then I will develop an understanding and understand theory as it is related to research, and inform personal stance on the merits of various traditions and their use in multicultural education. Thus, I will consider numerous topics such as, social construction of disability, multicultural education, and race. Moreover, in this paper, I will address multicultural education as a knowledge production movement by discussing Rosenqvist's theories in inclusive and diverse special education classes and adopting the idea of the enhancement of competence and the extension of independence. The enhancement of competence, for example, needs recognition of what the child brings to school, accepting his/her skills, attitudes, ways of thinking and social and language experience. Similarly, the extension of independence concentrates on cultural differences. However, the idea of independence may vary in different cultures.
\end{abstract}

Keywords: Diversity, Inclusion, Education, Mathematics, Multicultural education, Universal design for Learning (UDL).

Interviewing a leader in the Special Education Field

Jerry Rosenqvist is a professor of Special Education in the department of Educational and Psychological Research, School of Education, at Kristianstad University in Sweden. Professor Rosenqvist was born in 1945 in Sweden. He has worked as a primary and special education school teacher since 1969, and as a special education professor since 1988.

Rosenqvist has been a leader of research projects in special education since 1982, and highly respected in the field. He has conducted three major research projects about the function of schools for the mentally handicapped. Further, he has conducted an evaluation project of schools for the mentally handicapped in the Swedish County of Kronoberg. He is an expert within the Organization for Economic Cooperation and Development (OECD-project) "Active Life for Disabled Youth-Integration in the School" having participated in it from 1989-1995, and he has worked as a consultant for Swedish International Development Cooperation Agency (SIDA) and the World Bank in Pakistan, Jamaica and Tanzania. In the past he has been a special education teacher, especially for students with mental retardation. He has produced about 90 publications of different extent. He has also carried out a review of "Special Education Research Environment" for the Swedish National Board of Education. For the time being he is one of four authors working towards a revision of special education research, particularly schools for the mentally retarded (Rosenqvist, 2001).

I sent the interview questions to him via email and also talked to him by telephone. Additionally, I read some of his research and conference papers in order to illuminate his answers. Specifically I returned to the "International Special Education Congress 2000, Including the Excluded." His paper was "The Big Challenge" which focused on a deviant resource (Rosenqvist, 2001). "The big challenge" is - from a political and from an activity point of view-how the pre-school and the school should handle the fact that students have different prerequisites, experiences, knowledge, and needs. How can students differences appear as resources and make steering conditions for the pedagogical work in the school in a direction that is at best for all students? Rosenqvist added that the quotation can be seen as making distinct the ideological difference between traditional "special education" and the new approach of "special pedagogy," or between the meaning of being a "special education teacher" and "special pedagogue." In order to make this difference clear, both practically and ideologically Rosenqvist started up an investigation with the aim to find out and expose further obstacles to a developmental process towards a school for all (Rosenqvist, 2001). The aim of Rosenqvist's study is to contribute to a theory of special education. A more delimited aim is to reach a deeper understanding for how teachers, school leaders, and school politicians think about "day function" (Rosenqvist, 2001). Hill-Jackson, Sewell and Waters (2007) addressed the importance of multicultural education. Moreover, they pointed out teachers need to be multicultural...able to relate to many cultures with the knowledge, skills, and attitudes to better understand the growing student diversity.

\section{Different cultures}

J. Rosenqvist (personal communication, April 18, 2008) agrees that different cultures have different systems of knowledge. He added the idea that the dependence of government, commercial powers and other authorities could bias research results. This has also been studied by Butin (2002) whose research focuses on the productive use of power in 
education. Moreover, Reed and Black (2006) believe that valuing diversity in the class mean learning about the differences and similarities and finding ways to work which will lead to developing a culturally responsive curriculum and cross cultural understanding to help students build self esteem. Furthering this concept, Banks and Miller (2005) illustrated the challenge and difficulties in cross-cultural communication. They also focused on the ongoing neglect of language, and the lack of culturally rich curriculum knowledge.

To further examine this issue, Moran and Baker (2004) illustrated that the importance of knowing how to negotiate the politics at the universities, and in the field in general, is an important area of tacit knowledge. Thus, some scholars found that it is important to identify the people who had power, to cultivate and maintain positive relationships with them, and to generate resources. Another scholar in their study spoke of the effective use of information in building successful relationships. He believes that "If you want to influence people, you need to figure out who the right people to talk to are." In addition, Moran and Baker (2004) declared that because of specific emphasis in the No Child Left Behind legislation, the quality and usefulness of research in education is under increased public scrutiny and critique. The purpose of this close monitoring of scientifically based research and the restructuring within the U.S. Department of Education is to create and improve the quality of America's educational sciences. Even though Rosenqist's experience is not from within the United States and Moran and Baker's are, their experiences and bases of knowledge are still relevant to one another.

\section{The purpose of the research}

J. Rosenqvist (personal communication, April 18, 2008) mentioned that the purpose of his research is to help pave the road for people with disabilities in school and society so that they can live a more inclusive life. Recently, many research studies seem to have developed a newfound fascination with writing based in the humanities (Constas, 1998). This is related to Rosenqvist's research purpose and philosophy of multiculturalism. That is, all students, regardless of gender, social class, ethnic, racial, or cultural characteristics, should experience equal opportunity of education (Hill-Jackson et al., 2007). However, Obiakor (2007) assures equitable education, specifically multicultural special education that represents a realistic view of change needed as an integral part of general education.

Furthering this concept of disproportionate representation of human difference (Artiles, 1998) in his research Rosenqvist illustrates how school leaders and politicians, as well as teachers, parents, and students themselves, think about deviance and how deviance is defined. A certain focus input to issues like which students are assessed as deviant, how are these students categorized, and how are they taught? Agada (1998) observed that the purposes and practices of place-based education represent a huge challenge to many educators' assumptions about the way teachers and students should conduct teaching and learning. A critical pedagogy of place deepens the challenge by bringing cultural and ecological politics into the center of place-based discourse. Rosenqvist's research illustrates issues such as which students are assessed as deviant and how these students are categorized, and how and where they are taught (Rosenqvist, 2001). Moreover, Skiba, Poloni-Staudinger, Gallini, Simmons and Feggins-Aziz (2006) address the overrepresentation of minority students in certain disability categories in special education. As an example, Malloy and Malloy (1998) in their research demonstrated through theory and application that educators can teach mathematics to include more of the excluded students. However, they examined the educator's role in considering the culture of the students which gives them the power to be a part of the mathematics culture as they use the familiar knowledge of their culture.

Who should benefit from research? What is the government's role in defining research?

J. Rosenqvist (personal communication, April 18, 2008) mentioned that the research society and the people with different cultures and disabilities in school and society should benefit from research in every possible way. He added that the government should not define only support research issues. This is clear in Rosenqvist's articles "School for All" and "The Big Challenge." Both are from a political and from an activity point of view, how the pre-school and the school should handle the fact that students have different prerequisites, experiences, knowledge, and needs. For example, Sweden did, for a long time, set the tone as a promoter for integration in the school. During the last twenty years a wide range of countries have joined the approach and there has been an international movement towards integration in the school (Rosenqvist, 2001). To compare in the U.S.A and in U.K. an interesting theory has developed about the school in general is in progress aiming at finding a meta-theory of special education (Rosenqvist, 2001).

This reflects what Gruenewald (2003) illustrated about the importance of connecting schools with the social and ecological dimensions of place. Therefore, he mentioned that research in service learning, community based action, and school-community collaboration can offer direction. Moreover, Reed and Black (2006) concentrated on the importance of "reflecting and acting on the world to transform it." That is, to include, prepare and contribute to the teacher education, class, and culture within the political and economic system of the community. Next, Moran and Baker (2004) concentrated on personal passion and satisfaction. They added for some of the scholars, passion and satisfaction meant wanting to make schools a better place for children and having a profound concern for the fate of children in failing schools. In addition they emphasized social justice. Also, Reed and Black (2006) focused on social justice and activism in a way of managing behaviors and maintaining the status quo. 


\section{Who had an impact on Professor Rosenquist?}

In the area of multicultural professional development, education, social justice and knowledge J. Rosenqvist (personal communication, April 18, 2008) mentioned that a certain unnamed colleague professor of the same subject, a person with great empathy for issues of people with disabilities and special education, had particular impact on him. In order to understand the connection between Rosenqvist's mentor's ideas and other researcher's concepts further studies were examined. As an example Labaree (2003) pointed out some difficulties that are examined involving turning educational practitioners into educational researchers at American education schools. Teachers bring many traits that are ideal for this new role. At the same time, students and professors in researcher training programs often encounter a cultural clash between the world-views of the teacher and researcher. Baron (2007) further examined the importance of cultural ineptitude. He added systems, schools, and teachers are not intentionally culturally destructive, but rather they lack the knowledge they need to help minority students and communities. As a result this gap affects on the teachers attitudes and expectations. Labaree explained the concept of teaching and learning. He believed that "As far as I'm concerned what they pay me to do is to learn" (Labaree, 2003). That is if a person does not have high intrinsic motivation, a high level of curiosity, and love of learning he or she could not be a productive scholar. So, Labaree believes he/she should learn not teach as well.

To conclude, Rosenqvit's and Labarees paths are very similar because they had motivation, curiosity, love of learning and support to diverse multicultural students.

\section{Kind of research}

J. Rosenqvist (personal communication, April 18, 2008) mentioned that he is interested specifically in diversity issues, inclusion and access in society. He added Injustice and inequity issues in the area. This reflects what Moran and Baker (2004) mentioned about how educators learn to cope with the expectations and norms of their schools and to prioritize their time. In short, Rosenqvist adapted his interests and specialties to fit in with the requirements of his teaching. Salend (1999) illustrates the importance of the inclusion movement which will have positive impact on students with and without disabilities and their teachers. Moreover, he suggest that researchers and school district need to work together to validate and disseminate information about effective inclusion practices, policies, and programs that address the needs of students and teachers. Also, Van Garderen and Whittaker (2006) focus on the inclusive classroom and explain how the inclusion process can be helpful in meeting the needs of students from diverse backgrounds. Moran and Baker (2004) add that sometimes there were norms in their institutional settings that were counter to their developmental interests as scholars. Labaree (2003) argues like teachers, researches take moral responsibility for the consequences of education, and their work in trying to understand this institution is in large part motivated by their desire to rectify the harm done by dysfunctional education.

\section{Defining “Good” research}

J. Rosenqvist (personal communication, April 18, 2008) believes that good research equals engagement, honesty and discipline. Bad research is the opposite and may cause harm to the educational institute. According to Hostetler (2005), good education research is a matter not only of sound procedures but also of beneficial aims and results in order to serve people's well being. He added that good things need not be extraordinary. It is in the power of every researcher and educator to do something to improve the lives of people. In addition Day-Vines (2000) further examined and addressed educators' ethical responsibility for recognizing the dignity and worth of all students as well as enhancing teachers' multicultural competencies. Progress is not always easy, of course. It requires understanding, commitment, compassion, patience, and likely some amount of courage. In addition, education researchers have a particular obligation and opportunity because so much of a society's future depends on education. In order to see that a research is good Hostetler (2005) mentioned the importance of thinking beyond questions of studying students and analyzing school policies in order to making life better for people. He added serving people's well-being is a greater challenge, but it is also a great calling. To conclude, Baron (2007) mentioned that of all the civil rights, for which the world has fought and struggled, the right to learn is the most fundamental.

\section{Thinking about research}

To reflect on the concept of learning and the idea of "enhancement of competence and the extension of independence" J. Rosenqvist (personal communication, April 18, 2008) mentioned that his thinking about research has changed from dependence on certain methods and research areas to independence and self esteem.

To further this idea, Ladson-Billings and Donor (2005) illustrated a set of fundamental principles for a healthy community of researchers. These principles are:

- $\quad$ Posing significant questions that can be investigated empirically.

- Linking research to relevant theory.

- Using methods that permit direct investigation of the question. 
- $\quad$ Providing a coherent and explicit chain of reasoning.

- $\quad$ Replicating and generalizing across studies.

- $\quad$ Disclosing research to encourage professional scrutiny and critique.

Insert Figure 1 Here

To explain this idea J. Rosenqvist (personal communication, April 18, 2008) mentions that methods should always be dependent on and chosen as to a specific problem area and purpose of the research which will help in the researching, reasoning, disclosing, replicating and generalizing the study.

Hardings (1991) also distinguished between method and methodology. Method refers to techniques for gathering empirical evidence while methodology is the theory of knowledge and the interpretive framework that guides a particular research project. According to Moran and Baker (2004), there is a gap between the theoretical background and the methodological background. For this reason, it is important to fill in the gaps by learning through doing. That is, it is important to construct different research problems using different research designs and different methodologies.

\section{Assumptions about what we know?}

To J. Rosenqvist (personal communication, April 18, 2008), assumptions about how we come to know what we know can be through commitment and engagement in diverse studies and research in an honest way...

Moran and Baker (2004) have taken similar assumption as they showed that how important it is to the participants to manage not only their time but also their emotions when coping with the pressures of academic life the criticism inherent in the peer review process, and the politics of organizational life they formed collaborative networks for both emotional support and intellectual challenge. By making these knowledge structures more explicit, others may benefit from the thinking behind these scholars's success to improve scholarship in the multicultural education field.

\section{Challenges}

To further illustrate Rosenqvist's ideas Eisenhart and Dehaan (2005), suggest that the task of education scholars, researchers, and policy makers is to engage rather than exclude epistemologies in order to help in producing different knowledge and producing knowledge differently in a diverse, multicultural context.

To further collaborate on the absence of attention to social and political processes in addressing the problems of special education and its impact on diverse multicultural education researchers addressed these issues (Sleeter, 2000). To J. Rosenqvist (personal communication, April 18, 2008) his most significant challenge as an educator has been to reach "the diverse multicultural world." Banks and Miller (2005) also addressed these political issues of equity in both general and special education. Another study, focused on multicultural special education as an effective intervention for today's schools. Obiakor (2007) mentioned "language is a complex and unique characteristic of culture." To add clarification, Artiles (1998) focused on topics related to language difference of ethnic minority students.

To explain Rosenqvist's ideas of diverse education Thompson (2004) mentioned that it is very important to promote and protect the multicultural property of special education, to underscore the objective authority, to engage in surveillance of academic pedigrees, to read and write in a "universally" intelligible language (which, it goes without saying will be English), to assure readers of the lack of bias, and to show commitment. In regard to other subjects like mathematics, educators suggest teaching the subject to include more of the excluded students, especially minorities with diverse backgrounds. For these students exclusion is easy but inclusion is better. In this case, it is more beneficial if the educators consider the culture of the students which will be a part of the mathematics culture when they use the familiar knowledge of their culture and this will empower diverse students. Van Garderen and Whittaker (2006) focused on the principals of universal design for learning (UDL) in order to improve multicultural and diverse student's achievement. As for Moran and Baker (2004), they added that the scholar's interviews repeatedly showed sheer, dogged pursuit of what is necessary for productivity. According to their research, perseverance, focus, and dedication connected to maintain a clear research agenda and the willingness to write and rewrite until an appropriate level of clarity and understanding is achieved.

\section{Ethical considerations}

J. Rosenqvist (personal communication, April 18, 2008) a special education researcher believes that a scholar should be honest in all steps of the research project, to the people (or animals) involved, and to data, audience, and to show kind of humbleness. He adds that this is very much applicable in research involving people (students) with diverse backgrounds. Banks and Miller (2005) highlighted several legal and ethical issues in special education such as; the importance of developing culturally responsive tools that can identify the strengths and needs in a multidimensional fashion. Next, they emphasized the need for ongoing professional development.

Lontzenheiser (2007) pointed out that "opening with a brief contextualization of the ethical conundrums inherent in a qualitative research methodology, the researcher's interest is in methodologies that emanate from epistemologies that 
attempt both to be ethical, and to acknowledge the very impossibility of such a move." Next, Lontzenheiser outlines possibilities for data collection, analysis, and representation particularly important when working with queer youth. He added, the idea of ethical research would mean that power structures can be equalized. Both the researcher and the participants would be able to function as wholly conscious knowing actors who can be involved without the process of interrogating position, subject, object, or binaries.

As for Willower (2001), he mentioned that discussions of ethics in education have often been tied to political ideology, identity politics, and single concepts or ideas. These discussions have generally ignored the questions raised in philosophical treatments of ethics such as the relationship of ethics and knowledge or the processes of moral choice.

\section{Things to know}

In the interview Rosenqvist also discussed funding. He added how extremely difficult and frustrating is to raise funds. Obiakor (2007) focused on this issue in special education. He pointed out the importance of "free and appropriate public education for all learners including students with multicultural background."

Moran and Baker (2004) mentioned the urgency for funding research. They also added the importance of finding time for writing, publishing, and peer reviewing in order to improve the work as well as setting specific goals.

\section{Advice for beginning multicultural teachers}

Rosenqvist's advice is "Don't do it if you are not prepared to work hard and long time for little money!" (J. Rosenqvist, personal communication, April 18, 2008).

Eisenhart and Dehaan (2005) give recommendations for strengthening educational programs accordingly, with the aim of producing teachers who have a high degree of expertise and research skills in at least one area of educational investigation and a broad background of familiarity with the greater expanse of education-related research.

They also added that the nature of teaching can make things hard for programs that seek to turn teachers into effective researchers, and this problem of transition is exacerbated by institutional problems that make educational teaching and research so difficult. Of course, this is applied to individual teachers who will face tremendous pressure as beginning educators.

Moran and Baker (2004) emphasized the study participants and how they had learned to manage not only their time but also their emotions when coping with the pressures of academic life. Their comments indicated high levels of self-knowledge and self-regulation. They also had developed a high level of self-efficacy. A confidence in their ability to be successful that allowed them to sustain grueling work schedules.

\section{Implications}

The studies suggest cautious implications for practice and future diverse research. Multicultural education appears to be an easily-implemented academic intervention that could assist in effective drill and practice, and seems to be worthy of additional investigation. In order to develop a multicultural approach of teaching, a teacher must get to know the students.

Once familiar with the background of the students, a teacher can do some preliminary research about how the different cultures learn. Then the teacher can share this information with the students. By doing this, a teacher validates and includes students of diverse backgrounds. Teachers can then work individually in order to improve their self esteem and attitude toward multicultural education.

\section{Conclusion}

"If I have to, I can do anything. I am strong, I am invincible, and I am a teacher." (Helen Reddy). For me as a multicultural educator my voice in a changing world enables me to think in a broad spectrum of research on the state of education and help to live more inclusive lives. However, it is important to provide a forum for dialogue and discussion on issues of interest to educators in the fields of special education and culture emphasizing on the changing role of educators in the world which built strong bonds and links between learning and multiculturalism. Thus, if social and cultural values are encouraged and supported, through the use of contexts or through an acknowledgement of personal directions, then the teaching and learning will be more meaningful.

This reflects Rosenqvist's experience and describes the kind of research that he most typically does which as special education, inclusion and access in society, and injustice. However, the purpose of his research is to help diverse people with disabilities to live more inclusive lives. For this reason his research methods are always dependent on and chosen as to problem area and purpose of the research. Rosenqvist defines good research as working toward engagement, honesty and discipline.

As J. Rosenqvist (personal communication, April 18, 2008) claims to beginning researchers, "Don't do it if you are not prepared to work hard and long time for little money!" 


\section{References}

Agada, J. (1998). Multicultural education and the emerging paradigm: An essay in cultural epistemology. The Urban Review, 30(1), 77-95.

Artiles, A. J. (1998). The dilemma of difference: Enriching the disproportionality Discourse with theory and context. The Journal of Special Education, 32(1), 32-36.

Banks, S. R. (2004). Voices of tribal parents/caregivers who have children with special needs. Multiple Voices: Ethnically Diverse Exceptional Learners, 7(1), 33-47.

Banks, S. R., \& Miller, D. (2005). Empowering Indigenous families who have children with disabilities: An innovative outreach model. Disability Studies Quarterly, 25(2).

Baron, D. (2007, September). Cultural Proficiency: A Moral Imperative. Principal Leadership, 8(1), 52-54.

Butin, D. W. (2002). This ain't talk therapy: Problematizing and extending anti-Oppressive education. Educational Researcher, 31(3), 14-16.

Constas, M. (1998). The changing nature of educational research and a critique of postmodernism. Educational Researcher, 27(9), 36-42.

Day-Vines, N. L. (2000). Ethics, power, and privilege: Salient issues in the development of multicultural competencies for teachers serving African American children with disabilities. Teacher Education and Special Education, 23(1), $3-18$.

Einstein, A. (2010). "Quotations Book," Retrieved, January 2, from http://quotationsbook.com/quote/34064/.

Eisenhart, M. \& Dehaan, R. (2005). Doctoral preparation of scientifically based education researchers. Educational Researcher, 34(4), 3-13.

Gruenewald, D. (2003a). The best of both worlds: A critical pedagogy of place. Educational Researcher, 32(4), 3-12.

Harding, S. (1991). Whose science whose knowledge. Ithaca, NY: Cornell University Press, pp. 1-14, 181-190.

Hill-Jackson, V., Sewell, K. L., \& Waters, C. (2007). Having Our Say about Multicultural Education. Kappa Delta Pi Record, 43(4), 174-181. (action research).

Hostetler, K. (2005). What is "good" education research? Educational Researchers, 34(6), 16-21.

Judith Reed, Deborah J Black. (2006). Toward a Pedagogy of Transformative Teacher Education: World Educational Links. Multicultural Education, 14(2), 34-39.

Labaree, D. (2003). The peculiar problems of preparing educational researchers. Educational Researcher, 32(4), 13-22.

Ladson-Billings, G., \& Donnor, J. (2005). The moral activist: Role of critical race theory in scholarship. In N. Denzin and Y. Lincoln (Eds.) Sage handbook of qualitative research (pp. 279-301). Thousand Oaks: Sage.

Loutzeheiser, L. (2007). Working alterity: The impossibility of ethical research with youth. Educational Studies, 41(2), 109-127.

Malloy, C. E., \& Malloy, W. W. (1998). Issues of Culture in Mathematics Teaching and Learning. The Urban Review, 30(3), 245.

Moran, M. T., \& Baker, N. N. (2004). The Tacit Knowledge of Productive Scholars in Education. Teachers College Record, 106(7), 1484-1511.

Obiakor, F. E. (2007). Multicultural Special Education: Effective Intervention for Today's Schools. Intervention in School and Clinic, 42(3), 148-155

Reed, J., \& J Black, D. J. (2006). Toward a Pedagogy of Transformative Teacher Education: World Educational Links. Multicultural Education, 14(2), 34-39.

Rosenqvist, J. (2001). “The big challenge,” 1, 129-138. Retrieved, September 31, 2009, from http://hdl.handle.net/2043/725

Salend, S. (1999). The impact of inclusion on students with and without disabilities and their educators. Remedial and Special Education, 20(2), 114-126.

Skiba, R. J., Poloni-Staudinger, L., Gallini, S., Simmons, A. B., \& Feggins-Azziz, R. (2006). Disparate Access: The Disproportionality of African American Students With Disabilities Across Educational Environments. Exceptional Children, 72(4), 411-424.

Sleeter, C. E. (2000). Creating an Empowering Multicultural Curriculum. Race, Gender \& Class, 7(3), 178. 
Thompson, A. (2004). Gentlemanly orthodoxy: Critical race feminism, whiteness theory, and the APA manual. Educational Theory, 54(1), 27-57.

Van Garderen, D., \& Whittaker, C. (2006). Planning Differentiated, Multicultural Instruction for Secondary Inclusive Classrooms. Teaching Exceptional Children, 38(3), 12-20.

Willower, D. (2001). Epistemology, science, and moral practice. Interchange, 32(1), 1-16.

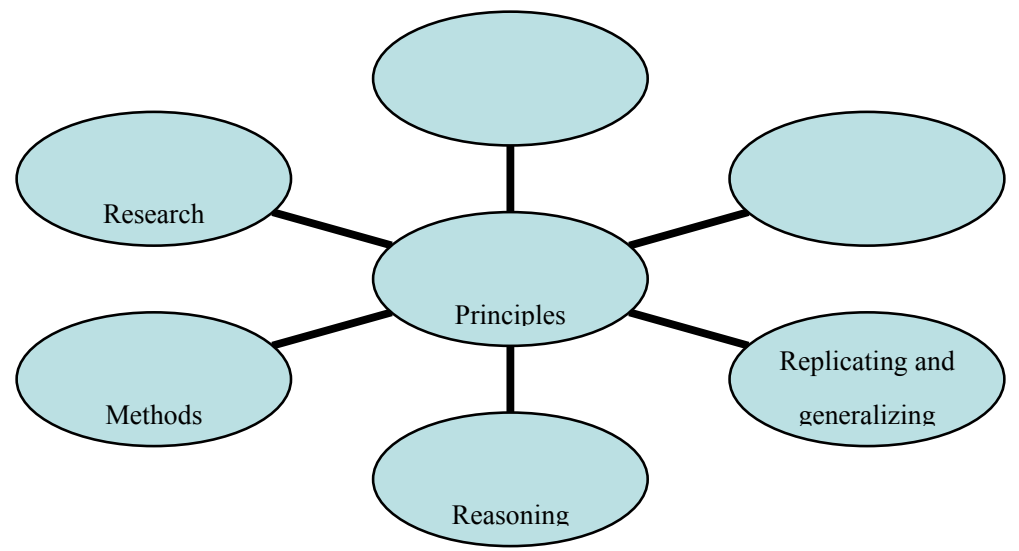

Figure 1. My rendering of Ladson-Billings and Donor's model

The relationship between the methods and the theoretical framework of the research 